\title{
The Application Effect of a Medical Information Management System for the Prevention of Depression in Mastectomy Patients
}

\author{
Seong-Ran Lee \\ Kongju National University \\ lsr2626@naver.com
}

\begin{abstract}
This study was conducted to examine the application effect of a medical information management system for the prevention of depression in mastectomy patients. The subjects were divided into an experimental group $(n=62)$ and a control group $(n=62)$. To verify the effects of the information mediation, this study used a progress method for measurement in the form of an application test and a follow-up test. The results of this study are as follows: First, it showed significantly the factors of health behavior on depression in the degree of education, nutrient intake, exercise, insomnia, and personality type $(p<.05)$. Secondly, it was found that the experimental group had a tendency toward gradually developing more variation from $70.2 \%$ to $83.1 \%$ in health behavior performance than the control group with regard to the measurement of depression over the application timeframe. Therefore, it is concluded that a medical information management system is effective in relieving mastectomy patients from depression over the physical, psychological, and social changes they experience.
\end{abstract}

Keywords: Application effect, Medical information management system, Depression, Mastectomy patients

\section{Introduction}

The incidence of breast cancer in South Korean women is rapidly increasing with the westernization of the South Korean lifestyle. Depression after mastectomy is the most common mental health problem confronting patients with breast cancer. It is estimated that $39.7 \%$ of mastectomy patients has a major depressive disorder [1]. Social support is a key ingredient in dealing with emotional distress and a critical point in helping people to cope with all kinds of extreme circumstances. Recently, despite the development of medical equipment and technology, the incidence of depression among mastectomy patients has increased every year. Currently, mastectomy patients account for about $7.2 \%$ of the total population of South Korea [2]. Depression is correlated with being older, experience of multiple diseases, grieving a recent loss, fewer neighbor visitors, and less participation in organized social activities[3,4]. The prevalence of organic mental disorders in mastectomy patients has increased as the Korean population ages. Mastectomy patients also suffer from functional disorders such as loneliness, depression, and despair that lead to suicide. These problems have their roots in the persons' social setting as well as their psychology. The proportion of the elderly who reported depression in a survey conducted in 2011 was 32.7\% $[2,4]$.

Unfortunately, previous studies shed insufficient light on the development of depression following mastectomy. Few studies have attempted to correlate this with clinically relevant outcomes. Therefore, it is important to implement new ideas to develop more medical information for the prevention of depression in mastectomy patients. This study seeks to 
examine the roots of post-mastectomy depression, but the most important significant aspect of this research is testing the mediation effect of medical information. Medical information can be provided systematically by the establishment of a database containing advanced clinical tests and their utilization methods [5, 7]. It is expected that the successful implementation of such a medical information system would help secure the foundation of advanced knowledge information infrastructure for the 21st century. It would also promote the satisfaction of mastectomy patience and the reliability of the services provided them through rapid service provision and diversified information sharing with the relevant patients, which would enhance the efficiency in handling the relevant diseases. In addition, it is expected that by providing depressive patients with correct and timely information by establishing a database that would provide for medical information management, the right to know of the patients would be satisfied and national competitiveness would be reinforced. Furthermore, the establishment of such a database is could contribute to the establishment of a systematical medical system that would assist in health assessment.

Thus, this paper aims to demonstrate the application effect of a medical information management system for the prevention of depression felt by mastectomy patients. This can be accomplished by establishing a medical information management system that can enhance service qualitatively and quantitatively. This will enable greater understanding of the psychological characteristics of depression.

\section{Materials and Methods}

\subsection{Materials}

This paper aims to investigate the effect of a medical information management system using standard-based data modeling of medical information sources. The design is as follows; First, a pilot information system was constructed and multi-center real-time trials were performed on it. [Figure 1]. Secondly, a medical information substructure was constructed and introduced to experts. Thirdly, medical information, integrated data technology and a knowledgebase were all developed. Fourthly, we predicted expected outcomes according to research development. Fifthly, we developed information sharing technology and an organic integration model of medical document and biological information. Sixthly, we developed linkages between the medical information management system with the appropriate governmental disease control, prevention research, and medical practice systems.

\subsection{Methods}

The subjects were 124 patients who visited general surgery at two general hospitals in Seoul, South Korea. The subjects were classified into an experimental group $(n=62)$ and a control group $(\mathrm{n}=62)$. The survey was performed using a self-reported questionnaire on intention to participate in a depression-prevention program. The chi-square test was used to analyze the demographic characteristics of the study subjects. The t-test or ANOVA was done to compare the experimental and control groups for assessing the effect of health behaviors on depression. On the other hand, multiple linear regression analysis was performed to examine the multivariate relationship between changes of physical and psychiatric situations in the experimental and control groups. Both groups were done to compare before and after three weeks of the mediation program. 


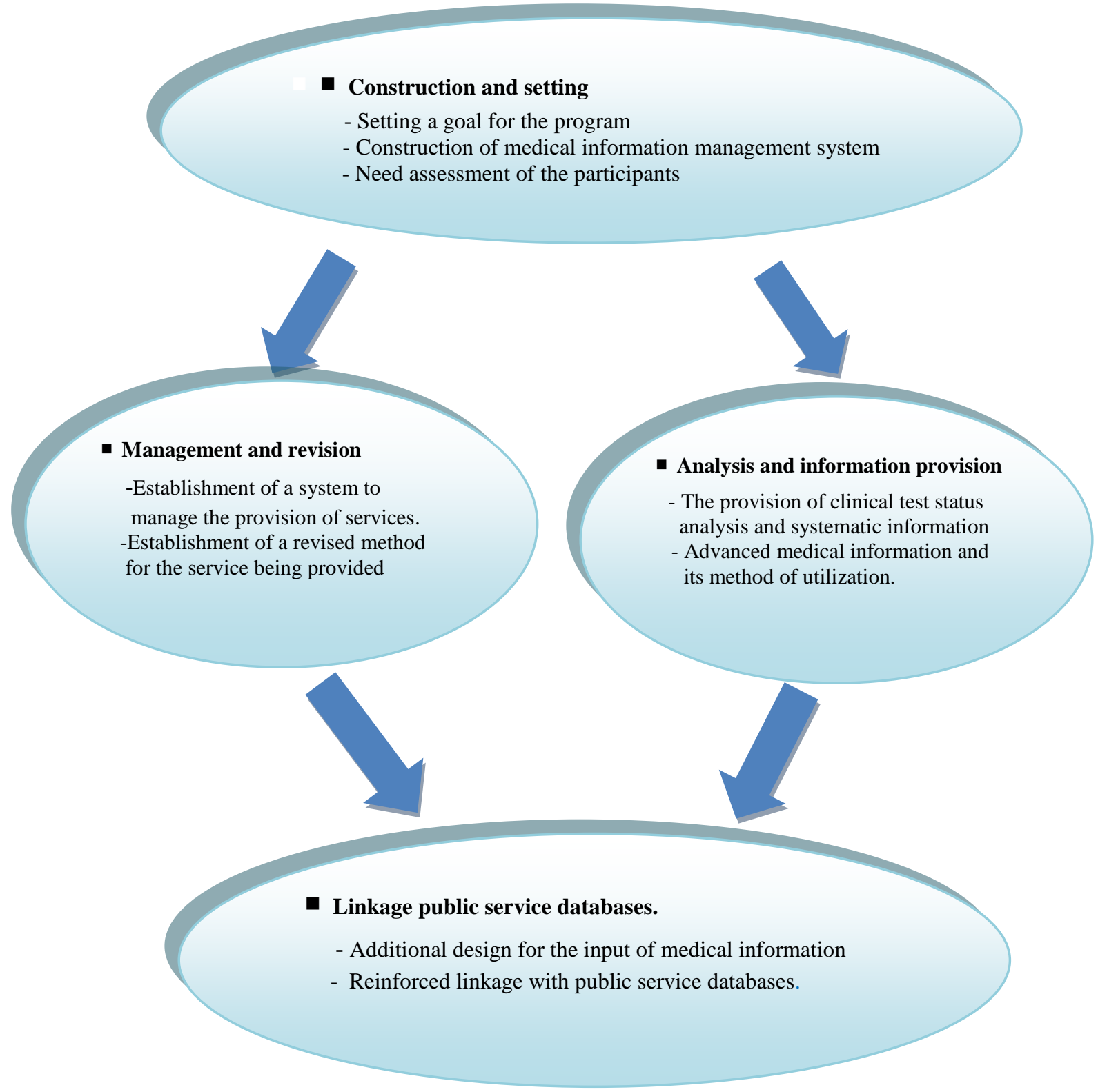

Figure 1. Construction of Medical Information Substructure for the Prevention of Depression

\section{Result}

\subsection{Demographic Characteristics of Study Subjects}

Table 1 shows the demographic characteristics of the study subjects. The response rate (72.6\%) of the experimental group was statistically significantly higher than the response rate (58.1\%) of the control group at over the age of 50 years $\left(\mathrm{X}^{2}=11.52, \mathrm{p}=.035\right)$ according to the age of the subjects. Also, for the introvert personality type $\left(\mathrm{X}^{2}=7.51, \mathrm{p}=.019\right)$, the response 
rate (46.8\%) of the experimental group was significantly higher than the response rate (24.2\%) of the control group.

Table 1. Demographic Characteristics of Study Subjects

\begin{tabular}{|c|c|c|c|c|}
\hline \multirow[b]{2}{*}{ Variables } & $\begin{array}{c}\text { Experimental } \\
\text { group }\end{array}$ & $\begin{array}{l}\text { Control } \\
\text { group }\end{array}$ & \multirow[b]{2}{*}{$X^{2}$} & \multirow[b]{2}{*}{ p } \\
\hline & $\mathrm{N}(\%)$ & $\mathrm{N}(\%)$ & & \\
\hline \multicolumn{5}{|l|}{ Age } \\
\hline$\leq 39$ & $5(8.1)$ & $7(11.3)$ & 11.52 & .035 \\
\hline $40-49$ & $12(19.4)$ & 19(30.6) & & \\
\hline $50-56$ & $28(45.2)$ & $15(24.2)$ & & \\
\hline$\geq 60$ & $17(27.4)$ & 21(33.9) & & \\
\hline \multicolumn{5}{|l|}{ Marital status } \\
\hline Single & $15(24.2)$ & $19(30.6)$ & 9.68 & .175 \\
\hline Married & $47(75.8)$ & $43(69.4)$ & & \\
\hline \multicolumn{5}{|l|}{ Educational level } \\
\hline Under high s. $\dagger$ & $16(25.8)$ & $14(22.6)$ & 13.19 & .026 \\
\hline High school & $27(43.5)$ & $31(50.0)$ & & \\
\hline Over high s. $\dagger$ & $19(30.6)$ & $17(27.4)$ & & \\
\hline \multicolumn{5}{|l|}{ Personality types } \\
\hline Introvert & 29(46.8) & $15(24.2)$ & 7.51 & .019 \\
\hline Extrovert & 11(17.7) & 21(33.9) & & \\
\hline Intermediate & $22(35.5)$ & $26(41.9)$ & & \\
\hline \multicolumn{5}{|l|}{ Employed } \\
\hline Yes & 20(32.3) & $28(45.2)$ & 5.26 & .082 \\
\hline No & $42(67.7)$ & $34(54.8)$ & & \\
\hline \multicolumn{5}{|l|}{ Religion } \\
\hline No religion & $13(21.0)$ & $15(24.2)$ & 10.83 & .947 \\
\hline Protestantism & 21(33.9) & $23(37.1)$ & & \\
\hline Buddhism & $14(22.6)$ & $12(19.4)$ & & \\
\hline Catholicism & $9(14.5)$ & $10(16.1)$ & & \\
\hline Others & $5(8.1)$ & $2(3.2)$ & & \\
\hline Total & $62(100.0)$ & $62(100.0)$ & & \\
\hline
\end{tabular}

\subsection{Factors Related to Health Behavior in Mastectomy Patients}

Table 2 presents the factors related to health behavior in mastectomy patients. Interestingly, the number of non-smoking respondents(3.51 \pm 0.64$)$ was significantly higher than the number of smokers (3.06 \pm 0.79$)$ in the experimental group. As for nutrient intake, more of the control group took in sufficient nutrients than insufficient nutrients $(\mathrm{t}=2.05, \mathrm{p}=.017)$.

Table 2-A. Factors Related to Health Behavior in Mastectomy Patients

\begin{tabular}{|c|c|c|c|c|c|c|}
\hline \multirow[b]{2}{*}{ Variables } & $\begin{array}{c}\text { Experimental } \\
\text { group }\end{array}$ & \multirow[b]{2}{*}{$\mathrm{F}$} & \multirow[b]{2}{*}{$\mathrm{p}$} & $\begin{array}{c}\text { Control } \\
\text { group }\end{array}$ & \multirow[b]{2}{*}{ F } & \multirow[b]{2}{*}{$\mathrm{p}$} \\
\hline & Mean \pm S.D. & & & Mean \pm S.D. & & \\
\hline \multicolumn{7}{|l|}{ Smoking } \\
\hline Non-smoker & $3.51 \pm 0.64$ & 3.68 & .042 & $3.18 \pm 0.79$ & 3.85 & .061 \\
\hline Former smoker & $3.27 \pm 0.81$ & & & $3.25 \pm 0.56$ & & \\
\hline Current smoker & $3.06 \pm 0.79$ & & & $3.34 \pm 0.72$ & & \\
\hline \multicolumn{7}{|l|}{ Drinking } \\
\hline No drinking & $3.29 \pm 0.93$ & 1.92 & .169 & $3.74 \pm 0.78$ & 1.93 & .152 \\
\hline Occasional & $3.78 \pm 0.71$ & & & $3.47 \pm 0.62$ & & \\
\hline Frequent & $3.52 \pm 0.65$ & & & $3.15 \pm 0.54$ & & \\
\hline
\end{tabular}


Table 2-B. Factors Related to Health Behavior in Mastectomy Patients

\begin{tabular}{|c|c|c|c|c|c|c|}
\hline \multirow[b]{2}{*}{ Variables } & \multicolumn{3}{|l|}{ Experimental group } & \multicolumn{3}{|l|}{ Control group } \\
\hline & Mean \pm S.D. & $\mathrm{t} / \mathrm{F}$ & $\mathrm{p}$ & Mean \pm S.D. & $\mathrm{t} / \mathrm{F}$ & $\mathrm{p}$ \\
\hline \multicolumn{7}{|c|}{ Nutrient intake } \\
\hline Insufficient & $3.73 \pm 0.74$ & 4.05 & .042 & $2.19 \pm 0.53$ & 2.05 & .017 \\
\hline Balanced & $2.54 \pm 0.52$ & & & $4.81 \pm 0.77$ & & \\
\hline \multicolumn{7}{|l|}{ Exercise } \\
\hline None & $4.15 \pm 0.36$ & 1.96 & .017 & $2.19 \pm 0.59$ & & \\
\hline Occasional & $2.69 \pm 0.85$ & & & $4.05 \pm 0.92$ & 3.69 & .019 \\
\hline Frequent & $1.87 \pm 0.91$ & & & $2.54 \pm 0.77$ & & \\
\hline \multicolumn{7}{|l|}{ Insomnia } \\
\hline Never & $1.05 \pm 0.62$ & 2.48 & .029 & $2.47 \pm 0.16$ & 3.54 & .036 \\
\hline Occasional & $4.57 \pm 0.59$ & & & $2.60 \pm 0.52$ & & \\
\hline Frequent & $3.92 \pm 0.74$ & & & $1.94 \pm 0.38$ & & \\
\hline \multicolumn{7}{|c|}{ Depressive symptoms } \\
\hline Never & $1.09 \pm 0.84$ & 1.57 & .183 & $1.42 \pm 0.59$ & 1.72 & .271 \\
\hline Occasional & $4.25 \pm 0.59$ & & & $3.42 \pm 0.61$ & & \\
\hline Frequent & $3.14 \pm 0.67$ & & & $1.76 \pm 0.55$ & & \\
\hline \multicolumn{7}{|c|}{ Mental discipline } \\
\hline Low & $3.36 \pm 0.65$ & -2.53 & .065 & $3.63 \pm 0.79$ & 2.45 & .065 \\
\hline Normal & $2.57 \pm 0.54$ & & & $3.51 \pm 0.83$ & & \\
\hline High & $4.12 \pm 0.91$ & & & $3.76 \pm 0.74$ & & \\
\hline \multicolumn{7}{|c|}{$\begin{array}{l}\text { Consulting related to } \\
\text { depression }\end{array}$} \\
\hline No & $2.45 \pm 0.79$ & 1.69 & .038 & $3.69 \pm 0.75$ & 1.86 & .073 \\
\hline Yes & $3.82 \pm 0.52$ & & & $2.85 \pm 0.52$ & & \\
\hline
\end{tabular}

\subsection{Determinants of Depression in Mastectomy Patients}

Table 3 presents the determinants of depression in mastectomy patients. This study showed that the influential factors on depression in both groups were the educational level, insomnia, nutrient intake, personality type, and exercise. Prediction of the impact of nutrient intake on the depression of mastectomy patients using multiple linear regression analysis was a significant factor $(p=.036)$. For two groups, exercise significantly predicted the level of depressive behaviors $(\mathrm{p}=.027)$. The explanatory power of $\mathrm{R}^{2}$ on depressive behaviors accounted for $32.6 \%$ of this correlation.

Table 3. Determinants of Depression in Mastectomy Patients

\begin{tabular}{lcccc}
\hline Variables & B & S.E. & $\beta$ & $\mathrm{P}$ \\
\hline Smoking & 0.119 & 0.076 & 0.072 & .206 \\
Age & 0.007 & 0.004 & 0.095 & .183 \\
Educational level & -0.055 & 0.057 & -0.051 & .049 \\
Insomnia & 0.151 & 0.139 & 0.089 & .025 \\
Nutrient intake & 0.030 & 0.091 & 0.018 & .036 \\
Personality type & -0.035 & 0.035 & -0.042 & .048 \\
Exercise & -0.091 & 0.083 & -0.049 & .027 \\
Depression level & 0.032 & 0.035 & 0.038 & .352 \\
Consulting & -0.539 & 0.157 & -0.144 & .167 \\
experience & & & & .349 \\
Fatigue & -0.232 & 0.038 & -0.250 & \\
\hline $\mathrm{R}^{2}$ & & 0.326 & & \\
\hline
\end{tabular}




\subsection{Change of Health Behavior After Application between Two Groups}

Figure 2 presents the change of health behavior after application between the two groups. According to the medical information application, the experimental group had higher health behavior than the control group.

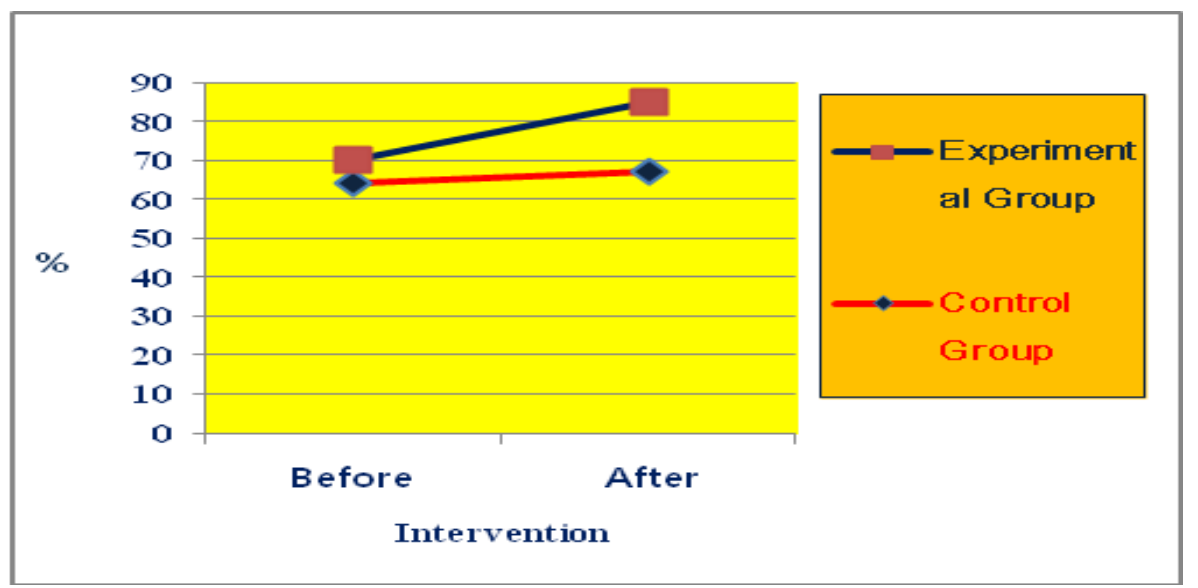

Figure 2. Change of Health Behavior after Application between the Two Groups

\subsection{Change of Psychiatric Status after Application between Two Groups}

Figure 3 presents the change of psychiatric status after application between the two groups. As for psychiatric status, the experimental group showed an increase in all forms of psychiatric status than the control group after information application.

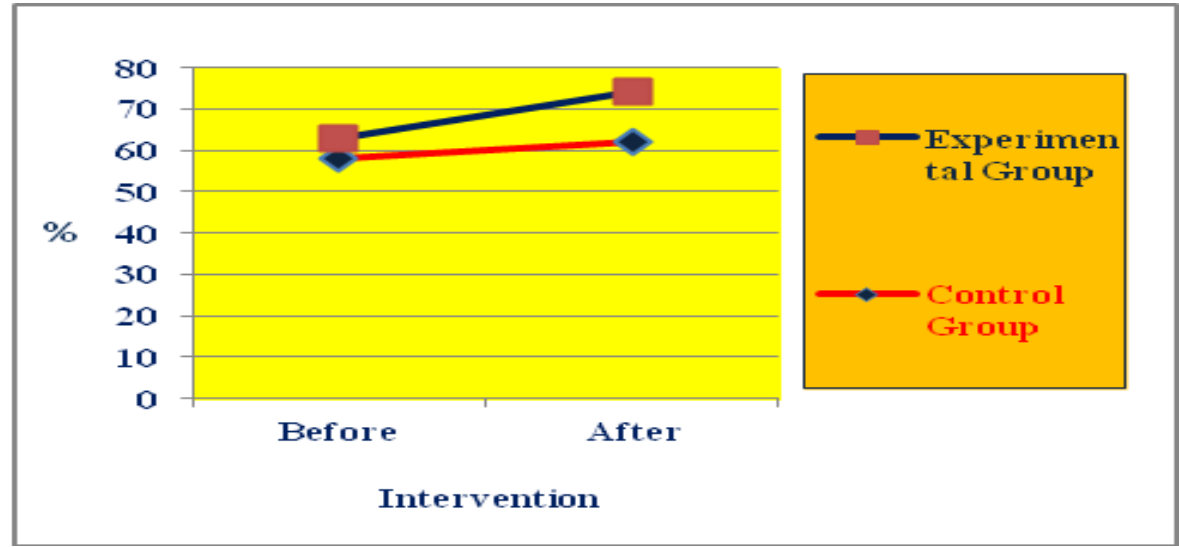

Figure 3. Change of Psychiatric Status after Application between the Two
Groups

\section{Discussion}

The aim of this study was to confirm differences in awareness and performance before and after health practice for mastectomy patients to estimate information effect. The level of factors is compared between experimental and control groups to identify lifestyle through statistical analysis. Based on the result, this paper identified the factors that are related to depression and the lifestyle of the patients. As a result of the study, this paper found out 
that healthy behavior was associated with lower levels of depression and isolation. This also can assist in curing depression.

As a result of this study, the control group showed a higher variety of nutrient intake. This finding was similar with those of previous studies on mental disease [8,9]. This study suggests that individuals with depression should be targeted for specific information intervention to cure and prevent the progression of the disease. This research result showed that the experimental group had higher levels of insomnia than the control group. This was also similar with a previous study [3]. It showed that subjects with sleep-inducing music experienced better sleep than those with eyeshields and earplugs [10,11]. Based on this finding, sleep-inducing music using earphones would be a meaningful part of information intervention programs to control sleep problems.

This study showed that the health behaviors of patients with depression were associated with various factors such as nutrient intake and sleep level, which suggests that these factors should be considered in the planning of a systemic education program. Through the results of this study, some useful and practical data on medical information and depressive prevention can be obtained [12, 13]. The application of medical information has showed the effect of extending intervention changes and spreading technology $[14,15]$. These results suggest that mental discipline and strengthening exercise programs are suitable for post-mastectomy depression. It analyzed the change of recognition about the subjects and learning about health practices after applying medical information to actual life. Although further studies are needed, the present work suggests that medical information may be an effective model for the prevention of depression after mastectomy.

The major goal of medical information is enhancing the relationship between patients and the social environment. The effect of social support on patients' psychological distress is very important. This study suggests that government or policy makers should pay attention to improving the physical health of depressive patients and preventing depression or stress in patients in order to decrease their suicide rate. Future studies should systematically examine structural and functional social support that could reduce patients' psychological depression and provide a better understanding of exactly what type of social support interventions are best for reducing specific types of problems and depression.

\section{Conclusion}

The study aims to demonstrate a prediction model of a medical information management system for the prevention of depression after mastectomy. As a result of this study, it was found that the experimental group had a tendency toward gradually developing more variation from $70.2 \%$ to $83.1 \%$ in health behavior performance than the control group with regard to the measurement of depression over the application timeframe. The present results showed that medical information about mediation programs for the prevention of depression plays a promising protective role against depression after mastectomy. Furthermore, information application prevents depressive patients from feeling useless. Therefore, it increased the depressive patients' sense of control over their lives. Use of this predictive model can be expanded to treat the disease of other patients, not only in counseling depressive patients but also in developing and carrying out programs with chronic diseases and approaching depression individually through databases and computer programming.

In conclusion, the medical information management system of this study was conducted by applying the proposed methods for mediation, and its information effect was evaluated. According to the results of verifying the mediation effect measured statistically, it has been proven that medical information is effective in the prevention depression after mastectomy. 


\section{References}

[1] J. H. Choi, K. H. Seo and I. D. Chung, “Conservative surgery for early breast cancer”, J. Korean Surg Soc, http://kmbase.medic.co.kr, vol. 45, (2011), pp. 763- 771.

[2] C. Suh, K. A. Suh, S. H. Park, H. J. Chang, J. W. Ko and D. H. Ahn, “Annual report of the central cancer registry in Korea”, J Korean Cancer Association, http://www.cancer.gov, vol. 32, (2011), pp. 87-89.

[3] B. Fisher, M. Bauer, R. Margolese, R. Poisson, Y. Pilch and C. Redmond, "Five-year results of a randomized clinical trial comparing total mastectomy with or without radiation in the treatment of breast cancer”, $\mathrm{N}$ Engl J Med, http://kmbasemedic, co.kr, vol. 312, (2005), pp. 667-671.

[4] J. Svehom, G. Kitagata and T. Kinoshita, "A practical design and implementation of active information resource based network management system”, IJEIC, www.sersc.org/journals, vol. 2, (2011).

[5] K. V. Santhosh and B. K. Roy, "An intelligent flow measurement technique using ultrasonic flow meter with optimized neural network”, IJCA, www.sersc.org/journals, (2012), pp. 185-196.

[6] W.-H. Wu, P.-C. Ko, P.-C. Lin and M.-H. Su, "Applying mobile agent to a mobile stock intermediary services system development”, IJSH, www.sersc.org/journals, vol. 2, (2008), pp. 10-12.

[7] Z. Xu, Y. Yin and J. Wang, "A density-based energy-efficient clustering algorithm for wireless sensor networks”, IJFGCN, www.sersc.org/journals, vol. 6, (2013), pp. 79-86.

[8] J. M. Simoni, H. D. Montoya, B. Huang and E. Goodry, "Social support and depressive symptomatology among HIV, positive women: the mediating role of social self-esteem and mastery. women and health”, J Psychosom, http://img.ksti.re.kr, vol. 42, no. 1, (2005), pp. 13-15.

[9] R. W. Robin and B. Roberts, "Low self-esteem prospectively predicts depression in adolescence and young adulthood”, Journal of Personality and Social Psychology, http://osen.mt.co.kr/article/G1007010071, vol. 95, (2008), pp. 695-708.

[10] X.-L. Li, "A particle waran optimization and immune theory-based algorithm for structure learning of bayesian networks”, IJDAT, www.sersc.org/journals, vol. 3, (2010), pp. 64-70.

[11] S. J. McPhee, J. A. Bird, D. Fordham, J. E. Rodnick and E. H. Osborn, "Promoting cancer prevention activities by primary care physicians, results of a randomized, controlled trial”, JAMA, http://www.mediatoday.co.kr/article.View.html?idxno=96524, vol. 266, (2008), pp. 29-36.

[12] I. W. Thompson and D. Callagher, "Depression and its treatment in the elderly, aging 40”, J of Medical Care, http://osen.mt.co.kr/article/G1009160047, (2005), pp. 14-18.

[13] A. Mishra, "Quality of experience based policy control framework for RTP based video and non-voice media sessions”, IJFGCN, www.sersc.org/journals, vol. 4, (2011), pp. 81-90.

[14] I. Bjelland, A. A. Dahl, T. T. Hang and D. Neckelmann, "The validity of the hospital anxiety and depression scale, An updated review”, J Psychosom Res, www.sio.org/iso/en.catalogue detail, vol. 52, (2008), pp. 69-77.

[15] S. J. Lepore, R. C. Silver, C. B. Wortman and H. A. Wayment, "Social constraints, intrusive thoughts, and de pressive symptoms among bereaved mothers”, J Pers Soc Psychol, http://img. kisti.re.kr, vol. 70, (2006), pp. 276-282.

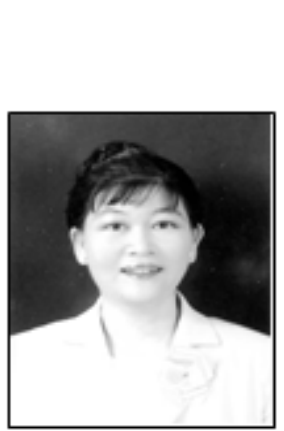

\section{Author}

Seong-Ran Lee received the B.S. degree in Consumer Science from Seoul National University, Korea in 1987. She received the M.S. degree in Public Health from Seoul National University, Korea in 1992 and $\mathrm{Ph} . \mathrm{D}$ in the same area from Catholic Medical College, Seoul, Korea in 2000. Currently, she is an Associate Professor in the Department of Medical Information at Kongju National University, Korea. Her present research interest is medical information. 